\title{
Global \& Community Health: Acute ischemic stroke in Toronto and Manila
}

\section{Bridging the gap}

Sanskriti Sasikumar, MD, and Jose Danilo Bengzon Diestro, MD

Neurology ${ }^{\circledR}$ 2020;95:604-606. doi:10.1212/WNL.0000000000010007
Correspondence

Dr. Sasikumar

Sanskriti.sasikumar@

mail.utoronto.ca

\begin{abstract}
The educational experience of a neurology trainee can have profound regional variations. We recount the management of a stroke code in Toronto, Canada, and Manila, Philippines, as a means to highlight the need for collaborative learning, both in terms of practicing evidence-based medicine and managing neurologic conditions in resource-limited settings. Concerted peer-led initiatives such as videoconference rounds are an easy and cost-effective means of unifying this experience.
\end{abstract}

\section{Toronto, Ontario, Canada: 5:45 AM}

I wake up to the startling drone of the pager. Through bleary eyes, I recognize a STAT page and jolt out of the call-room bed and towards the phone. I call the operator: "Neurology? It's another stroke code, estimated time of arrival is 6 minutes." This page has alerted everyone on the on-call stroke team, including the attending neurologist, interventionalist, and stroke nurse. As I run downstairs to the emergency department, I take a brief look at the NIH Stroke Scale (NIHSS) card in my scrub pocket, thankful that it provides a succinct language with which I can communicate the severity of the stroke to my attending staff. Time is brain, after all.

I meet the patient as she is being wheeled into the emergency department. While the paramedics steer the stretcher into its allocated room, we discuss the circumstances of the patient's presentation: "57year-old female, last seen normal at 11 PM last night... had woken up at 5 AM this morning to use the washroom only to find that she could not get out of bed because she could not move her right side..." I pause my incessant questioning - "Is she on blood thinners? What is her medical history? Was there a witnessed seizure?" - as we transfer the patient onto the bed. Within seconds, there are a flurry of arms around her, obtaining vital signs, drawing bloodwork, weighing her...

I proceed to examine the patient through this intricate and well-practiced routine. Using the methodical maneuvers of the NIHSS, I detect left gaze preference, global aphasia, right hemiplegia, and hemisensory loss. She has a complete left middle cerebral artery syndrome. The porter arrives just as the patient's leads are attached to a portable monitor, and we rush her to the CT scanner. The synergistic relationship of the health care team is intended for one purpose: to figure out the nature of this patient's weakness and give her the best chance at survival.

The patient woke up with her symptoms, so she is out of the treatment window for thrombolysis. Her only hope for recovery is endovascular thrombectomy, so I hope that her imaging detects a proximal occlusion with easily accessible vasculature to retrieve the clot. As I wait for the imaging results, I access an all-Ontario patient information portal to gather prior medical information about the patient, to understand what she was like before she lost the ability to explain it to us.

From the Division of Neurology (S.S.) and Division of Diagnostic and Therapeutic Neuroradiology, Department of Medical Imaging, St Michael's Hospital (J.D.B.D.), University of Toronto, Canada.

Go to Neurology.org/N for full disclosures. Funding information and disclosures deemed relevant by the authors, if any, are provided at the end of the article. 
Once the technician alerts me that the CT angiogram is done, I run to the radiology reading room. As expected, there is an occlusion of the left middle cerebral artery, at the M1 segment, with well-preserved parenchyma and a near-complete mismatch on CT perfusion. By now, my attending physician arrives to the radiology suite, and I hastily convey the story. We liaise with our interventional radiology colleagues, who have already reviewed the scan, and agree that the patient is a great candidate for endovascular thrombectomy.

The patient's family has arrived by now, and provide urgent consent for the procedure. The patient is rushed to the thrombectomy suite, and within 20 minutes, the team is trailing a catheter through her femoral artery and making their way up to the clot. It takes them 30 minutes to retrieve the clot, and within minutes, she begins to move her right leg. With a sigh of relief, I follow her to the intensive care unit, where she will be closely monitored for the next 24 hours.

\section{Manila, Philippines: 8:30 AM}

"Brain attack team to the emergency room now." I rush out of the stroke unit and head for the new patient. Every second counts. Because most of our stroke patients are uncoordinated transfers from primary or secondary centers, prehospital notification is the exception rather than the rule. After navigating through our hot, humid, and chaotic emergency room, I spot one of the neurology residents by the triage table. The patient is a 72year old man, arriving an hour after witnessed sudden onset severe right sided weakness and global aphasia. After inserting an IV line and excluding hypoglycemia, we bring him straight to the scanner. On the way there, we examine him and get an NIHSS of 22. I suspect a main trunk occlusion of the left middle cerebral artery. A plain CT scan shows no signs of a bleed or early ischemic changes: an Alberta Stroke Program Early CT Score of 0 . Despite having a functioning catheterization laboratory and attendings trained to perform the procedure, our patients are unable to afford the stent retriever and aspiration devices needed for mechanical thrombectomy. Thus, none of them undergo the procedure. We skip the CT angiogram and I call my stroke attending to relay the case. "Go ahead. Give alteplase."

We go straight to our stroke unit, where the senior resident is waiting with the IV thrombolytic drug (alteplase). After we obtain informed consent from the patient's relatives, the first bolus of the drug goes in. I look at my watch: 41 minutes from door time. It is well below the recommended 60 minutes of the American Stroke Association guidelines. Not bad for my second thrombolysis as our hospital's sole stroke fellow. If we did not have to wait for the ongoing abdominal CT to finish, we would have been faster. After the adrenaline wears off, I think about how recanalization for large vessel occlusion is unlikely without mechanical thrombectomy. Three years after the landmark trials for endovascular thrombectomy revolutionized the treatment of acute ischemic stroke, funding for the devices in our public health care system is still not in place. Still, slow and steady progress, championed by my stroke service attendings, is being made. Four years prior, when I was a first-year neurology resident, we had no stroke cases undergoing IV thrombolysis because no one could afford the drug. Now, our hospital stocks alteplase, always available at zero cost for the next patient with ischemic stroke.

A day later, the patient has not improved. A repeat plain head CT confirms the findings of a main trunk infarct involving the left cerebral hemisphere, and worsening edema from the infarct prompts us to call neurosurgery. The patient undergoes a decompressive hemicraniectomy later that day. After 12 days, he goes home still hemiplegic and globally aphasic. A private hospital, 20 minutes away from ours, caters to patients who can afford to pay for the full cost of mechanical thrombectomy. Had my patient belonged to that socioeconomic class, he probably would have had a very different outcome. Advances of modern medicine expand the gap between indigent and affluent patients even further in developing countries like mine without a true universal health care system. I will work with what we have. Like I always have. "Brain attack team to the emergency room now." Back to the grind. I have a full year of patients with stroke waiting.

\section{Discussion}

The global burden of stroke is increasing, affecting 15 million people annually, ${ }^{1}$ and its associated disability disproportionately affects low- and middle-income countries compared to highincome nations. Much of the world's population has limited access to vital stroke services such as endovascular thrombectomy and IV thrombolysis. ${ }^{2}$ The Philippine General Hospital is ahead of most other public hospitals in the developing world in terms of access to alteplase, stroke neurologists, and an acute stroke unit, but implementation of ideal stroke management is limited by the cost of endovascular devices. ${ }^{3}$ Limited financial support and lack of trained personnel in developing countries further contribute obstacles to stroke care. ${ }^{4}$ While governments and international organizations are obligated to address these discrepancies, physicians also have a responsibility to educate and increase awareness where it is needed most.

The cases above highlight the disparities in the experiences of neurology trainees around the world. Common conditions like stroke can be managed differently depending on access to resources, which can encourage reliance on either clinical acumen or advanced diagnostics. Peer-led collaboration between institutions is a means to bridge this gap in trainee exposure, whereby countries can share their regional strengths in the management of neurologic conditions. While programs based in high-income countries can showcase investigational and interventional modalities, those in developing nations can give insight into more cost-effective solutions that work in their setting.

On-the-ground international efforts can be expensive and challenging to organize, but teleconferencing offers an inexpensive and reliable alternative. The University of Toronto Neurology International Resident Videoconference and 
Exchange is a monthly resident-led educational rounds consisting of 7 international sites and spanning 4 continents. Aside from providing exposure to a variety of cases, the program fosters a platform for international collaboration, discussion of global health topics, and dialogue about the challenges each site faces in delivering optimal care for neurologic conditions. The program has further facilitated resident exchanges and fellowships, resulting in a more globally integrated neurology experience. Breadth of clinical exposure is vital for all neurology trainees, so it is important to create opportunities that encourage participation in medical education and recognize the value of shared experiences.

\section{Study funding}

No targeted funding reported.

\section{Disclosure}

The authors report no disclosures relevant to the manuscript. Go to Neurology.org/N for full disclosures.
Appendix Authors

\begin{tabular}{lll}
\hline Name & Location & Contribution \\
\hline $\begin{array}{l}\text { Sanskriti } \\
\text { Sasikumar, MD }\end{array}$ & $\begin{array}{l}\text { University of } \\
\text { Toronto, } \\
\text { Canada }\end{array}$ & $\begin{array}{l}\text { Conception, execution, and write- } \\
\text { up of first draft of the manuscript }\end{array}$ \\
\hline $\begin{array}{l}\text { Jose Danilo } \\
\text { Bengzon } \\
\text { Diestro, MD }\end{array}$ & $\begin{array}{l}\text { University of } \\
\text { Toronto, } \\
\text { Canada }\end{array}$ & $\begin{array}{l}\text { Write-up of first draft and } \\
\text { reviewing the manuscript }\end{array}$ \\
\hline
\end{tabular}

\section{References}

1. Feigin VL, Roth GA, Naghavi M, et al. Global burden of stroke and risk factors in 188 countries, during 1990-2013: a systematic analysis for the Global Burden of Disease Study 2013. Lancet Neurol 2016;15:913-924.

2. Tsang AC, Yang IH, Orru E, et al. Overview of endovascular thrombectomy accessibility gap for acute ischemic stroke in Asia: a multi-national survey. Int J Stroke 2019: 1747493019881345 .

3. Diestro JDB, Omar AT, Sarmiento RJC, et al. Cost of hospitalization for stroke in a low-middle-income country: findings from a public tertiary hospital in the Philippines. Int J Stroke 2020:174749302090687.

4. Feigin VL, Norrving B, Mensah GA. Global burden of stroke. Circ Res 2017;120: 439-448. 


\section{Neurology}

\section{Global \& Community Health: Acute ischemic stroke in Toronto and Manila: Bridging the gap}

Sanskriti Sasikumar and Jose Danilo Bengzon Diestro

Neurology 2020;95;604-606 Published Online before print June 16, 2020

DOI 10.1212/WNL.0000000000010007

This information is current as of June 16, 2020

\section{Updated Information \& Services}

\section{References}

Subspecialty Collections

Permissions \& Licensing

Reprints including high resolution figures, can be found at: http://n.neurology.org/content/95/13/604.full

This article cites 2 articles, 1 of which you can access for free at: http://n.neurology.org/content/95/13/604.full\#ref-list-1

This article, along with others on similar topics, appears in the following collection(s):

Access to care

http://n.neurology.org/cgi/collection/access_to_care

All Cerebrovascular disease/Stroke

http://n.neurology.org/cgi/collection/all_cerebrovascular_disease_strok e

All Education

http://n.neurology.org/cgi/collection/all_education

All global neurology

http://n.neurology.org/cgi/collection/all_global_neurology

Inclusion, Diversity, Equity, Anti-racism, and Social Justice (IDEAS)

http://n.neurology.org/cgi/collection/all_equity_diversity_and_inclusio n

Information about reproducing this article in parts (figures,tables) or in its entirety can be found online at:

http://www.neurology.org/about/about_the_journal\#permissions

Information about ordering reprints can be found online:

http://n.neurology.org/subscribers/advertise

Neurology ${ }^{\circledR}$ is the official journal of the American Academy of Neurology. Published continuously since 1951, it is now a weekly with 48 issues per year. Copyright @ 2020 American Academy of Neurology. All rights reserved. Print ISSN: 0028-3878. Online ISSN: 1526-632X.

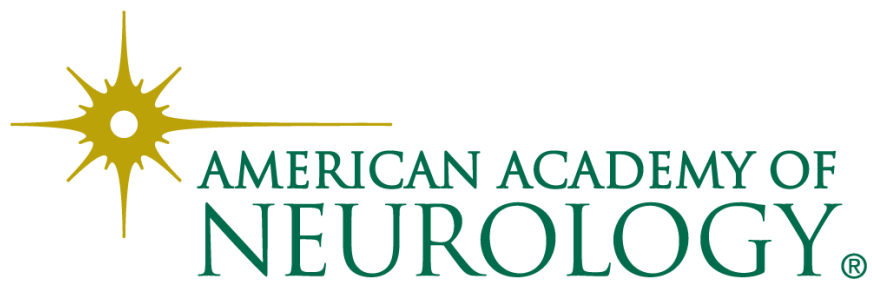

